Article

\title{
Trends in Treatment and Survival of Gallbladder Cancer in the Netherlands; Identifying Gaps and Opportunities from a Nation-Wide Cohort
}

\author{
Elise de Savornin Lohman ${ }^{1}$, Tessa de Bitter ${ }^{2}$, Rob Verhoeven ${ }^{1,3}{ }^{\circledR}$, Lydia van der Geest ${ }^{3}$, \\ Jeroen Hagendoorn ${ }^{4}$, Nadia Haj Mohammad ${ }^{5}$, Freek Daams ${ }^{6}$, Heinz-Josef Klümpen ${ }^{7}$, \\ Thomas van Gulik ${ }^{8}$, Joris Erdmann ${ }^{8}$, Marieke de Boer ${ }^{9}$, Frederik Hoogwater ${ }^{9}$ (D), \\ Bas Groot Koerkamp ${ }^{10}$, Andries Braat ${ }^{11}$, Joanne Verheij ${ }^{12}$, Iris Nagtegaal ${ }^{2}$, \\ Cornelis van Laarhoven ${ }^{1}$, Peter van den Boezem ${ }^{1}$, Rachel van der Post ${ }^{2}$ and Philip de Reuver ${ }^{1, *}$ \\ 1 Department of Surgery, Radboud University Medical Centre, 6500 HB Nijmegen, The Netherlands; \\ elise.desavorninlohman@radboudumc.nl (E.d.S.L.); R.Verhoeven@iknl.nl (R.V.); \\ kees.vanlaarhoven@radboudumc.nl (C.v.L.); peter.vandenboezem@radboudumc.nl (P.v.d.B.) \\ 2 Department of Pathology, Radboud University Medical Centre, 6500 HB Nijmegen, The Netherlands; \\ tessa.debitter@radboudumc.nl (T.d.B.); Iris.Nagtegaal@radboudumc.nl (I.N.); \\ chella.vanderpost@radboudumc.nl (R.v.d.P.) \\ 3 Department of Research, Netherlands Comprehensive Cancer Organization, \\ 3501 DB Utrecht, The Netherlands; l.vandergeest@iknl.nl \\ 4 Department of Surgery, Utrecht University Medical Center, 3508 GA Utrecht, The Netherlands; \\ j.hagendoorn-3@umcutrecht.nl \\ 5 Department of Medical Oncology, Utrecht University Medical Center, Utrecht University, 3508 GA Utrecht, \\ The Netherlands; n.hajmohammad@umcutrecht.nl \\ 6 Department of Surgery, Amsterdam University Medical Centers, VU University, Cancer Center Amsterdam, \\ 1007 MB Amsterdam, The Netherlands; f.daams@amsterdamumc.nl \\ 7 Department of Medical Oncology, Amsterdam University Medical Centers, University of Amsterdam, \\ Cancer Center Amsterdam, 1100 DD Amsterdam, The Netherlands; h.klumpen@amsterdamumc.nl \\ 8 Department of Surgery, Amsterdam University Medical Centers, University of Amsterdam, Cancer Center \\ Amsterdam, 1100DD Amsterdam, The Netherlands; t.m.vangulik@amsterdamumc.nl (T.v.G.); \\ j.i.erdmann@amsterdamumc.nl (J.E.) \\ 9 Department of Surgery, Section of HPB-Surgery and Liver Transplantation, University Medical Center \\ Groningen, 97700 RB Groningen, The Netherlands; m.t.de.boer@umcg.nl (M.d.B.); \\ f.j.h.hoogwater@umcg.nl (F.H.) \\ 10 Department of Surgery, Erasmus MC, 3000 CB Rotterdam, The Netherlands; \\ b.grootkoerkamp@erasmusmc.nl \\ 11 Department of Surgery, Leiden University Medical Center, 2300 RC Leiden, The Netherlands; \\ a.e.braat@lumc.nl \\ 12 Department of Pathology, Amsterdam University Medical Center, 1100 DD Amsterdam, The Netherlands; \\ j.verheij@amsterdamumc.nl \\ * Correspondence: philip.dereuver@radboudumc.nl; Tel./Fax: +31-24-3613983
}

Received: 9 March 2020; Accepted: 3 April 2020; Published: 9 April 2020

\begin{abstract}
Gallbladder cancer (GBC) is rare in Western populations and data about treatment and outcomes are scarce. This study aims to analyze survival and identify opportunities for improvement using population-based data from a low-incidence country. GBC patients diagnosed between 2005 and 2016 with GBC were identified from the Netherlands Cancer Registry. Patients were grouped according to time period (2005-2009/2010-2016) and disease stage. Trends in treatment and overall survival (OS) were analyzed. In total 1834 patients were included: 661 (36\%) patients with resected, $278(15 \%)$ with non-resected non-metastatic, and $895(49 \%)$ with metastatic GBC. Use of radical versus simple cholecystectomy $(12 \%$ vs. $26 \%, p<0.001)$ in early (pT1b/T2) GBC increased. More patients with metastatic GBC received chemotherapy (11\% vs. $29 \%, p<0.001)$. OS improved from
\end{abstract}


4.8 months $(2005-2009)$ to 6.1 months $(2010-2016)(p=0.012)$. Median OS increased over time (2005-2009 vs. $2010-2016)$ in resected (19.4 to 26.8 months, $p=0.038$ ) and metastatic (2.3 vs. 3.4 months, $p=0.001) \mathrm{GBC}$ but not in unresected, non-metastatic GBC. In early GBC, patients with radical cholecystectomy had a median OS of 76.7 compared to 18.4 months for simple cholecystectomy $(p<0.001)$. Palliative chemotherapy showed superior $(p<0.001)$ survival in metastatic $(7.3$ versus 2.1 months) and non-resected non-metastatic (7.7 versus 3.5 months) GBC. In conclusion, survival of GBC remains poor. Radical surgery and palliative chemotherapy appear to improve prognosis but remain under-utilized.

Keywords: gallbladder neoplasms; cohort studies; chemotherapy; surgery; epidemiology

\section{Background}

Gallbladder cancer (GBC) is a rare and highly lethal neoplasm of the biliary tract. GBC demonstrates marked geographic, age-, gender-, and ethnicity-related differences in incidence, implying (epi)genetics or environmental factors may play an important role in the development of GBC [1-6]. Other possible risk factors include cholelithiasis, obesity, gallbladder polyps, chronic infections, and an abnormal pancreaticobiliary duct junction $[1,7,8]$.

Treatment of GBC remains challenging. Diagnosis-unless incidentally after cholecystectomy for benign gallbladder disease-is often made in an advanced stage and survival is extremely poor due to the limited efficacy of systemic therapy options [3]. The only treatment with curative intent is surgical resection. However, due to late detection and a tendency towards invasive local growth, only $10 \%$ to $25 \%$ of tumors are candidates for potential curative intent surgery at presentation $[9,10]$. Even after resection 5-year survival rates are poor, ranging from $12 \%$ to $40 \%$ in non-incidental tumors $[3,11,12]$. Long-term survival is only observed in patients with early (T1/T2) GBC, which is mainly diagnosed incidentally. However, even for these patients, additional radical surgery with resection of the gallbladder bed and lymph node dissection of the hepatoduodenal ligament is recommended because it is thought to considerably increase survival $[13,14]$.

The limited benefit of systemic therapy in GBC has been shown in prospective trials; in 2010, the ABC-02 trial reported a median overall survival (OS) of 11.7 months vs. 8.1 months in unresectable biliary tract cancer treated with gemcitabine and cisplatin versus gemcitabine alone [15]. This has since been adopted as the standard regimen in the treatment of unresectable GBC. Although several randomized clinical trials have investigated the value of adjuvant chemotherapy for biliary tract cancers, none have found a survival benefit in the intention-to-treat analysis and no adequately powered subgroup analyses for GBC have been conducted [16,17].

Guidelines for the treatment of localized GBC are mainly based on retrospective evidence and expert opinion due to the minimal availability of randomized evidence. Previous studies investigating GBC have typically been conducted in high-volume, non-Western centers and included patients with various biliary tract cancers $[15,18,19]$. Due to presumed different etiologies, results in GBC may differ from those in other biliary tract tumors [20].

Our objective was to investigate trends in treatment, establish prognostic factors associated with survival and identify opportunities for improvement in treatment stratified for disease stage.

\section{Methods}

This is a cohort study using data from the nationwide population-based Netherlands Cancer Registry (NCR), containing information on all newly diagnosed malignancies. The NCR receives notifications from the automated pathological archive (PALGA), the nation-wide network and registry of histo- and cytopathology in the Netherlands, and is supplemented by alerts from the National Archive of Hospital Discharge Diagnosis [21]. Completeness of the registry is estimated to be at least 
$95 \%$ [22]. Since all data was anonymized a waiver for ethical approval was provided. The STROBE guidelines for reporting of observational studies have been followed [23]. This study was approved by the NCR ethical review board and a waiver for ethical approval was provided by the Medical Ethics Review Committee of the region Arnhem-Nijmegen (CMO A-N, nr. 2017-3912) on 27/12/2017. The study was conducted according to the Declaration of Helsinki. Anonymized patient level data are available upon request from the Netherlands Cancer Registry. The statistical code is available upon request from the corresponding author.

\subsection{Patient Selection and Variable Definitions}

Clinicopathological data on all adult patients diagnosed between 2005 and 2016 with invasive gallbladder neoplasms were extracted. The following variables were provided: age, gender, year of diagnosis, socioeconomic status (social deprivation scores based on a mean number of 4000 inhabitants per 4-digit postal codes), histopathological or clinical diagnosis, tumor histology (based on the ICD-O3 classification, morphological codes are provided in Appendix A), clinical and pathological TNM stage (AJCC staging system, version 6 for patients diagnosed from 2005 to 2009 and version 7 from 2010 to 2016 [24,25]), presence and location of metastatic disease, occurrence of syn- or metachronous primary tumors, type of resection performed, resection margin (R0: microscopically free of tumor, R1 microscopically positive for tumor, R2: macroscopically positive for tumor), systemic therapy (yes/no), radiation therapy (yes/no), and duration of follow-up in days from date of diagnosis. Missing data occurred in four out of nine baseline variables ( $2 \%$ to $29 \%$ ) and was not imputed because it was determined not to be missing at random.

Primary radical/extended cholecystectomy was defined as cholecystectomy with en-bloc excision of the gallbladder bed and dissection of the hepatoduodenal lymph nodes as the first surgery received by the patient. Re-resection was defined as any surgery for GBC after initial cholecystectomy alone within 180 days of diagnosis. Radicality was classified into R0 (resection margin microscopically free of tumor) and R1/2 (resection margin micro- or macroscopically positive). Supportive therapy included endoscopic procedures, biliary drainage and metastasectomy. Ninety-day mortality was defined as death within 90 days of diagnosis. Chemo- and radiotherapy were defined as administration of at least one dose. Information regarding type of systemic therapy received was not available. Follow-up data on vital status (complete until February 2018) were provided by linkage to the automated Municipal Personal Records Database.

\subsection{Quality Control and Completeness of Data Assessment}

Accuracy of diagnosis and completeness of histopathological assessment was assessed by comparing data from the resected patients provided by the NCR with data extracted from the medical records available from four academic centers in the Netherlands: Radboudumc, Amsterdam University Medical Center (location AMC), Erasmus MC and Leiden University Medical Center.

\subsection{Statistical Analysis}

Characteristics were described using counts and percentages for continuous variables and means and ranges for continuous variables. $\chi$-square testing or Fisher's exact test, where appropriate, were used to assess differences in patient characteristics. Incidence rates were calculated per 100,000 person years and age-standardized using the European standard population. Trends in incidence were assessed by calculating the estimated annual percentage change (EAPC).

Patients were grouped according to T-stage (T1/T2 vs. T3/T4), N-stage (N0 vs. N1/N2) and resection margin (R0 vs. R1/R2 vs. Rx). For survival analyses, patients were categorized as resected, non-metastatic non-resected (i.e., inoperable patients due to comorbidities and/or locally advanced disease) or metastatic at diagnosis. To assess trends in treatment over time, patients were grouped according to period of diagnosis (Period 1; 2005-2009 and Period 2; 2010-2016; these periods coincide with the introduction of gemcitabine-cisplatin chemotherapy as standard of care for unresected BTC). 
A subgroup analysis in patients with early (T1b/T2) disease was conducted to assess trends in surgical treatment. Kaplan-Meier curves were used to calculate median OS. OS was defined as time in days from date of diagnosis until date of death from any cause or the date of last follow-up (February 2018). Patients alive at the last date of follow-up were censored. Cox regression analysis was used to calculate hazard ratios for potential prognostic factors. Covariates were selected based on literature and entered in the multivariable model when statistically relevant $(p<0.1)$ on univariable analysis. $p$-values $<0.05$ were considered statistically significant. All tests of significance were two-tailed. Statistical analyses were conducted using the SPSS 24.0 statistical package (SPSS, Inc., Chicago, IL).

\section{Results}

\subsection{Incidence and Patient and Tumor Characteristics}

Patient and tumor characteristics are shown in Table 1. Between 2005 and 2016, 1834 patients were diagnosed with GBC in the Netherlands (Figure 1). Forty-nine percent of patients had metastatic disease at diagnosis (43\% from 2005 to 2009 and 53\% from 2010 to 2016, $p<0.001$ ). The incidence of GBC did not change significantly (EAPC $-0.7 \%, p=0.32$ ) over time (Appendix B). Median age at diagnosis was 71 (IQR 64-80) years. Eighty percent of patients had histopathological confirmation of diagnosis.

Table 1. Characteristics of patients with gallbladder cancer in the Netherlands (2005-2016).

\begin{tabular}{|c|c|c|c|c|}
\hline Cohort & $\begin{array}{c}\text { Total } \\
(n=1834)\end{array}$ & $\begin{array}{l}\text { Resected } \\
(n=661)\end{array}$ & $\begin{array}{l}\text { Non-resected } \\
\text { Non-metastatic } \\
(n=278)\end{array}$ & $\begin{array}{c}\text { Metastatic } \\
(n=895)\end{array}$ \\
\hline \multicolumn{5}{|l|}{ Patient and tumor characteristics } \\
\hline Age & $71.1(22-97)$ & $69.2(27-97)$ & $74.3(32-95)$ & $71.2(22-96)$ \\
\hline Male sex & $545(29.1 \%)$ & $206(31.2 \%)$ & $82(29.5 \%)$ & $250(27.9 \%)$ \\
\hline \multicolumn{5}{|l|}{ Socioeconomic Status } \\
\hline High & $501(26.8 \%)$ & $183(27.7 \%)$ & $82(29.5 \%)$ & $229(33.4 \%)$ \\
\hline Medium & $741(39.6 \%)$ & $253(38.3 \%)$ & $110(39.6 \%)$ & $367(41.0 \%)$ \\
\hline Low & $630(33.7 \%)$ & $225(34.0 \%)$ & $86(30.9 \%)$ & $299(33.4 \%)$ \\
\hline \multicolumn{5}{|l|}{ Clinicopathologic T stage $^{a}$} \\
\hline $\mathrm{T} 1$ & $526(28.1 \%)$ & $147(22.6 \%)$ & $1(0.4 \%)$ & $54(8.5 \%)$ \\
\hline $\mathrm{T} 2$ & & $303(45.8 \%)$ & $0(0.0 \%)$ & $22(2.5 \%)$ \\
\hline $\mathrm{T} 3 / \mathrm{T} 4$ & $643(34.3 \%)$ & $172(26.2 \%)$ & $169(60.8 \%)$ & $427(47.7 \%)$ \\
\hline $\mathrm{TX}$ & $496(26.5 \%)$ & $38(5.8 \%)$ & $13(4.7 \%)$ & $302(33.7 \%)$ \\
\hline Unknown/missing & $207(11.1 \%)$ & - & $95(34.2 \%)$ & $90(10.1 \%)$ \\
\hline \multicolumn{5}{|l|}{ Clinicopathologic N stage $^{\text {a }}$} \\
\hline No & $674(36.0 \%)$ & $140(21.2 \%)$ & $62(22.3 \%)$ & $237(26.5 \%)$ \\
\hline N1 & $432(23.1 \%)$ & $123(18.6 \%)$ & $74(26.6 \%)$ & $331(37.0 \%)$ \\
\hline NX & $559(29.9 \%)$ & $387(58.5 \%)$ & $47(16.9 \%)$ & $237(26.5 \%)$ \\
\hline Unknown/missing & $207(11.1 \%)$ & $11(1.7 \%)$ & $95(34.2 \%)$ & $90(10.1 \%)$ \\
\hline \multicolumn{5}{|l|}{ Location synchronous metastases } \\
\hline Liver & $\mathrm{N} / \mathrm{A}$ & N/A & $\mathrm{N} / \mathrm{A}$ & $350(39.1 \%)$ \\
\hline Peritoneal & $\mathrm{N} / \mathrm{A}$ & $\mathrm{N} / \mathrm{A}$ & $\mathrm{N} / \mathrm{A}$ & $119(13.3 \%)$ \\
\hline Lymph node & $\mathrm{N} / \mathrm{A}$ & $\mathrm{N} / \mathrm{A}$ & $\mathrm{N} / \mathrm{A}$ & $46(5.1 \%)$ \\
\hline Lung & $\mathrm{N} / \mathrm{A}$ & N/A & N/A & $11(1.2 \%)$ \\
\hline Liver + peritoneum & $\mathrm{N} / \mathrm{A}$ & N/A & $\mathrm{N} / \mathrm{A}$ & $92(10.3 \%)$ \\
\hline Other & $\mathrm{N} / \mathrm{A}$ & N/A & N/A & $22(2.5 \%)$ \\
\hline Multiple, other & $\mathrm{N} / \mathrm{A}$ & $\mathrm{N} / \mathrm{A}$ & $\mathrm{N} / \mathrm{A}$ & $175(19.6 \%)$ \\
\hline Unknown/missing & N/A & N/A & N/A & $80(8.9 \%)$ \\
\hline Pathology confirmation of primary tumor(yes) & $1566(83.7 \%)$ & $661(100 \%)$ & $156(56.1 \%)$ & $732(81.8 \%)$ \\
\hline \multicolumn{5}{|l|}{ Differentiation grade } \\
\hline Well & $\mathrm{N} / \mathrm{A}$ & $102(15.4 \%)$ & N/A & N/A \\
\hline Moderate & $\mathrm{N} / \mathrm{A}$ & $209(31.6 \%)$ & $\mathrm{N} / \mathrm{A}$ & N/A \\
\hline Poor & $\mathrm{N} / \mathrm{A}$ & $157(23.7 \%)$ & $\mathrm{N} / \mathrm{A}$ & N/A \\
\hline Not determined & $\mathrm{N} / \mathrm{A}$ & $193(29.2 \%)$ & $\mathrm{N} / \mathrm{A}$ & $\mathrm{N} / \mathrm{A}$ \\
\hline \multicolumn{5}{|l|}{ Radicality } \\
\hline R0 & N/A & $417(63.1 \%)$ & N/A & N/A \\
\hline R1 & N/A & $130(19.7 \%)$ & N/A & N/A \\
\hline R2 & N/A & $24(3.6 \%)$ & $\mathrm{N} / \mathrm{A}$ & N/A \\
\hline Unclear & N/A & $90(13.6 \%)$ & $\mathrm{N} / \mathrm{A}$ & $\mathrm{N} / \mathrm{A}$ \\
\hline
\end{tabular}

\footnotetext{
${ }^{a}$ Clinical P- and N- for unresected patients and pathologic $\mathrm{T}$ - and $\mathrm{N}$ - stage for resected patients are provided.
} 


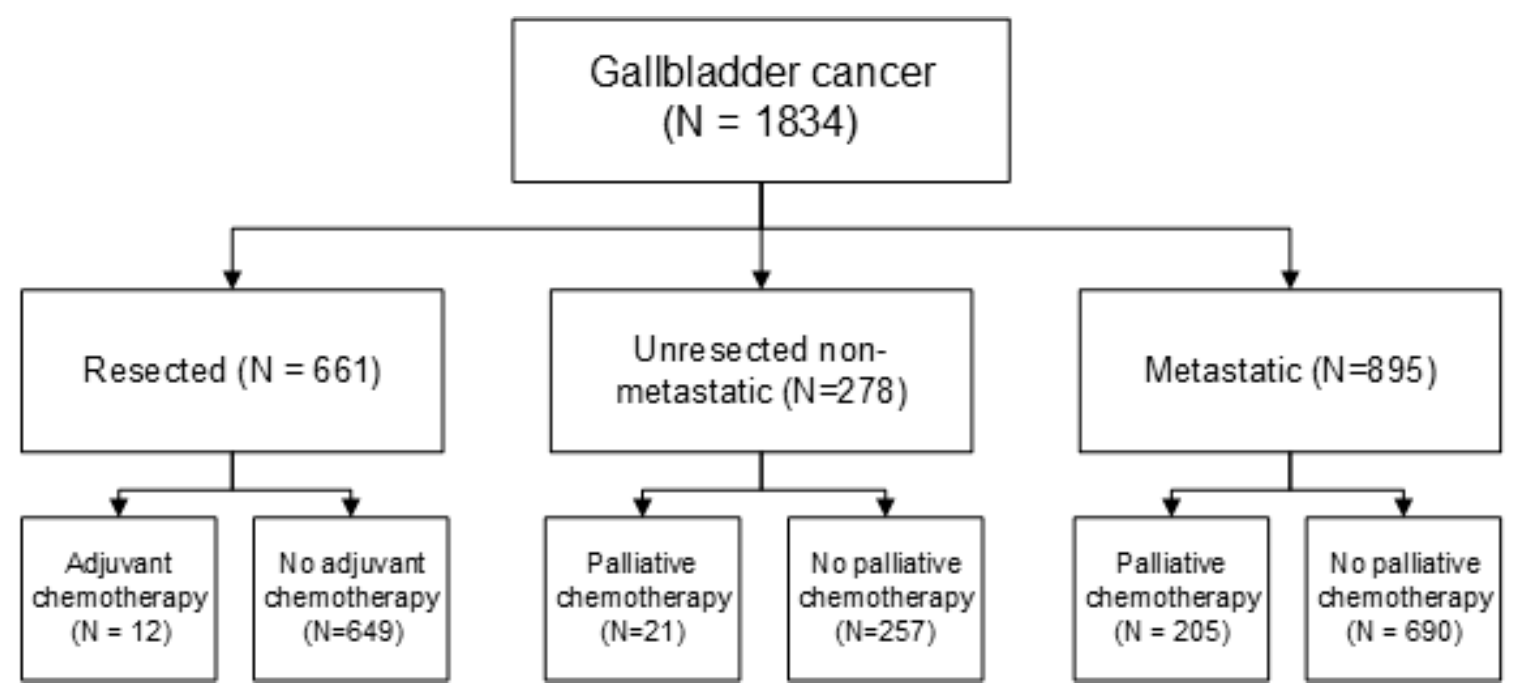

Figure 1. Patient flow.

\subsection{Treatment}

Time trends in treatment in resected, non-resected non-metastatic, and metastatic GBC are shown in Figure 2. Among all patients with non-metastatic disease, primary resection rates increased; $64.7 \%$ in 2005 to 2009 to $74.8 \%$ in 2010 to 2016 ( $p=0.001$ ). More extensive tumors (T3-T4) were resected between 2010 and 2016 compared to 2009 to 2015 (from 25.1\% to 33.1\%, $p<0.001$ ). In resected, non-metastatic patients, 90-day mortality decreased from $12.0 \%$ to $5.6 \%(p=0.003)$ and the percentage of patients receiving $\mathrm{R} 0$ resection did not change significantly (from $70.3 \%$ to $74.7 \%, p=0.294$ ). The number of patients receiving an extended cholecystectomy (with/without hepatoduodenal lymphadenectomy) opposed to simple cholecystectomy in early (T1b-T2) GBC increased significantly, from 19\% to 33\% ( $p$ $<0.001$ ). In the subgroup analysis conducted in patients with early GBC, 90-day mortality and the R0 resection rate did not change over time. Adjuvant chemotherapy was only administered to 12/661 $(1.8 \%)$ patients.

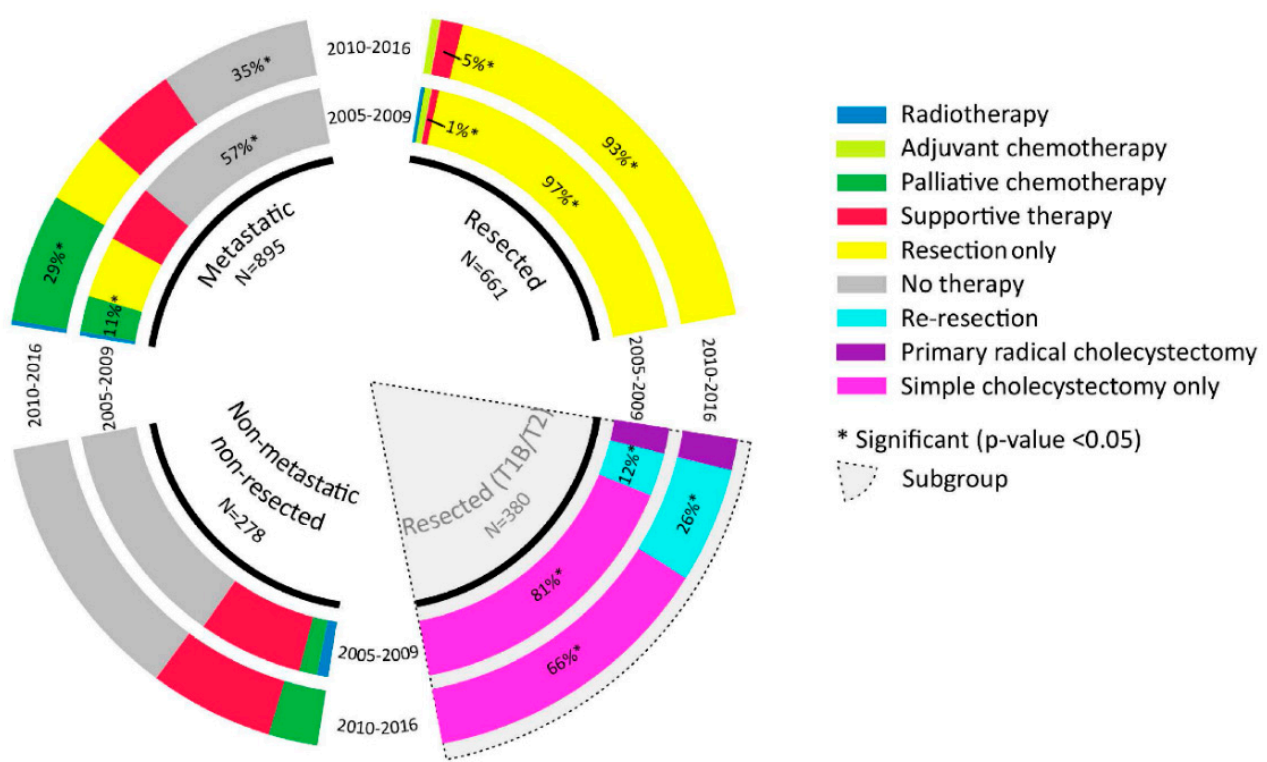

Figure 2. Trends in treatment in resected, non-resected non-metastatic, and metastatic gallbladder cancer (GBC). The grey area represents a subgroup analysis of resected patients with early (T1b/T2) gallbladder cancer. Percentages are only displayed when significant differences $(p<0.05)$ between periods were found. Supportive treatment includes endoscopic procedures, biliary drainage and metastasectomy. 
Use of palliative chemotherapy did not increase in patients with unresected, non-metastatic GBC ( $15 \%$ vs. $15 \%$, Figure 2). The use of palliative chemotherapy in metastatic GBC increased from $11 \%$ to $29 \%(p<0.001)$.

\subsection{Survival}

Median OS of the entire cohort was 5.5 months (95\% CI 5.0-6.0) and increased from 4.8 months (95\% CI 4.2-5.4) in 2005 to 2009 to 6.1 months (95\% CI 5.4-6.8) in 2010 to 2016 ( $p=0.012$ ) (Figure 3A). Median OS differed significantly between resected and non-metastatic non-resected/metastatic disease: 23.7 (95\% CI 19.6-27.8), 3.6 (95\% CI 3.1-4.6) and 2.7 (95\% CI 2.6-3.2) months, respectively $(p<0.001$, Figure 3B). Resected patients showed improved median OS over time; from 19.4 to 26.8 months ( $p$ $=0.038$, Appendix C). Median OS in metastatic patients increased from 2.3 to 3.4 months $(p<0.001$, Appendix C). In non-resected patients survival did not change significantly over time.

A
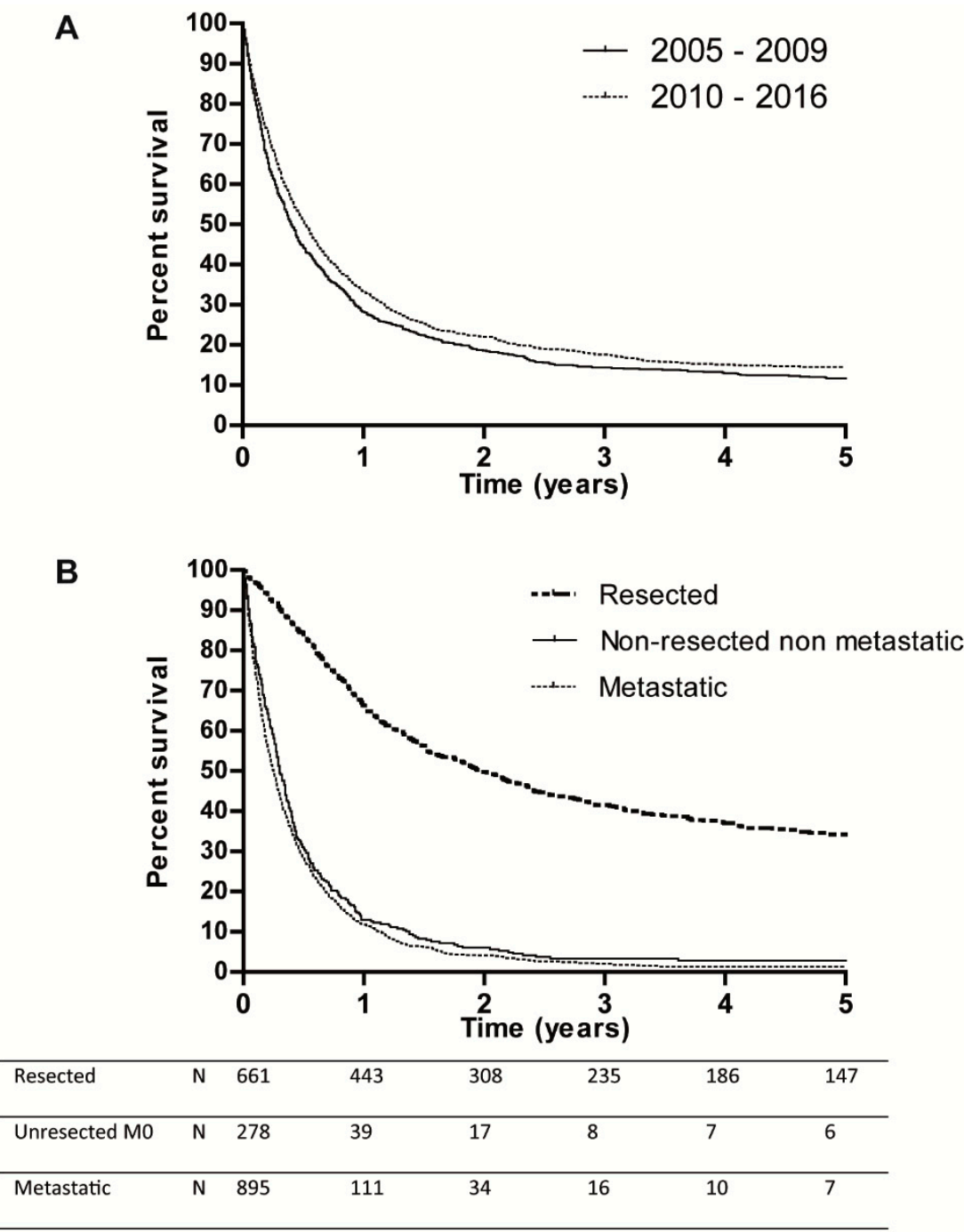

Figure 3. (A): Survival according to time period. (B): Survival according to disease stage.

\subsection{Therapy and Survival}

Survival in patient groups with resected, non-metastatic non-resected and metastatic GBC is shown in Table 2. The survival benefit of adjuvant chemotherapy could not be assessed since only 12 out of 661 patients received some form of adjuvant therapy. Radical surgery (either primary radical cholecystectomy or re-resection) in early GBC was associated with a significantly higher median OS compared to simple cholecystectomy, from 18.4 to 76.7 months $(p<0.001)$. Palliative chemotherapy in 
non-resected non-metastatic and metastatic disease was associated with superior survival; from 3.5 to $7.7(p=0.011)$ and 2.1 versus $7.3(p<0.001)$ months, respectively.

Table 2. Survival of patients with gallbladder cancer according to clinical stage and treatment strategy.

\begin{tabular}{|c|c|c|c|c|}
\hline Group & $\mathbf{N}$ & Five-year Survival & Median OS, Months (95\% CI) & Log Rank Test $p$ Value \\
\hline Total & 1895 & $13.2 \%$ & $5.5(5.0-6.0)$ & \\
\hline Resected non-metastatic & 661 & $34.2 \%$ & $23.7(19.6-27.8)$ & \\
\hline Adjuvant chemotherapy & 12 & $37.5 \%$ & $29.4(21.4-37.5)$ & \multirow{2}{*}{0.521} \\
\hline No adjuvant chemotherapy & 649 & $34.1 \%$ & $23.7(19.4-27.6)$ & \\
\hline T1b/T2 tumor, no radical surgery & 106 & $30.6 \%$ & $18.3(13.8-22.7)$ & \multirow{2}{*}{$<0.001$} \\
\hline T1b/T2 tumor, radical surgery & 274 & $52.7 \%$ & $76.7(43.0-110.3)$ & \\
\hline Non-resected non-metastatic & 278 & $2.9 \%$ & $3.6(3.1-4.1)$ & \\
\hline No palliative chemotherapy & 257 & $3.0 \%$ & $3.5(2.9-4.0)$ & \multirow{2}{*}{0.011} \\
\hline Palliative chemotherapy & 21 & - & $7.7(4.5-10.8$ & \\
\hline Metastatic & 895 & $1.3 \%$ & $2.9(2.6-3.2)$ & \\
\hline No palliative chemotherapy & 690 & $0.6 \%$ & $2.1(1.9-2.4)$ & \multirow{2}{*}{$<0.001$} \\
\hline Palliative chemotherapy & 205 & $3.7 \%$ & $7.3(6.4-8.2)$ & \\
\hline
\end{tabular}

\subsection{Prognostic Factors for Survival}

Poor prognostic factors were increasing age, poor tumor differentiation, higher T-stage, presence of lymph node metastases and (in resected patients) non-radical resection Table 3.

Table 3. Prognostic factors for patients with resected (A) and metastatic (B) gallbladder cancer.

\begin{tabular}{|c|c|c|c|c|c|c|}
\hline \multicolumn{7}{|c|}{ A. Prognostic factors for patients with resected gallbladder cancer. $N=661$. } \\
\hline \multirow{2}{*}{ Characteristic } & \multicolumn{3}{|c|}{ Univariable Cox Regression } & \multicolumn{3}{|c|}{ Multivariable Cox Regression } \\
\hline & HR & $95 \% \mathrm{CI}$ & $p$ Value & HR & $95 \% \mathrm{CI}$ & $p$ Value \\
\hline \multicolumn{7}{|l|}{ Grade } \\
\hline Well & 1 & & & 1 & & \\
\hline Moderate & 1.41 & $1.02-1.95$ & 0.036 & 1.17 & $0.84-1.61$ & 0.354 \\
\hline Poor & 2.67 & $1.93-3.70$ & $<0.001$ & 2.07 & $1.49-2.86$ & $<0.001$ \\
\hline Unknown & 1.45 & $1.05-1.99$ & 0.023 & 1.74 & $1.26-2.41$ & 0.001 \\
\hline \multicolumn{7}{|l|}{ Sex } \\
\hline Female & 1 & & & & & \\
\hline Male & 0.88 & $0.71-1.08$ & 0.214 & & & \\
\hline \multicolumn{7}{|l|}{ Pathological T stage } \\
\hline $\mathrm{T} 1$ & 1 & & & 1 & & \\
\hline $\mathrm{T} 2$ & 1.77 & $1.35-2.32$ & $<0.001$ & 1.58 & $1.19-2.10$ & 0.001 \\
\hline $\mathrm{T} 3 / \mathrm{T} 4$ & 3.59 & $2.69-4.78$ & $<0.001$ & 2.61 & $1.89-3.61$ & $<0.001$ \\
\hline $\mathrm{Tx}$ & 3.23 & $2.01-5.18$ & $<0.001$ & 2.16 & $1.34-3.50$ & 0.002 \\
\hline \multicolumn{7}{|l|}{ Pathological N stage } \\
\hline N0 & 1 & & & 1 & & \\
\hline N1 & 2.96 & $2.13-4.12$ & $<0.001$ & 1.95 & $1.39-2.74$ & $<0.001$ \\
\hline $\mathrm{Nx}$ & 2.48 & $1.86-3.31$ & $<0.001$ & 1.86 & $1.46-2.66$ & $<0.001$ \\
\hline \multicolumn{7}{|l|}{ Radicality } \\
\hline R0 & 1 & & & 1 & & \\
\hline $\mathrm{R} 1 / \mathrm{R} 2$ & 3.78 & $3.03-4.71$ & $<0.001$ & 2.69 & $2.11-3.43$ & $<0.001$ \\
\hline Unclear & 1.60 & $1.20-2.14$ & 0.001 & 1.48 & $1.10-1.98$ & 0.009 \\
\hline Adjuvant chemotherapy (yes) & 0.67 & $0.33-1.36$ & 0.268 & & & \\
\hline Prior malignancy (yes) & 1.22 & $0.93-1.61$ & 0.150 & & & \\
\hline Increasing age (years) & 1.04 & $1.03-1.05$ & $<0.001$ & 1.04 & $1.03-1.05$ & $<0.001$ \\
\hline
\end{tabular}


Table 3. Cont.

\begin{tabular}{|c|c|c|c|c|c|c|}
\hline \multicolumn{7}{|c|}{ B. Prognostic factors for patients with metastatic gallbladder cancer. N = 895 . } \\
\hline \multirow{2}{*}{ Characteristic } & \multicolumn{3}{|c|}{ Univariable Cox Regression } & \multicolumn{3}{|c|}{ Multivariable Cox Regression } \\
\hline & HR & $95 \% \mathrm{CI}$ & $p$ Value & HR & $95 \% \mathrm{CI}$ & $p$ Value \\
\hline \multicolumn{7}{|l|}{ Grade } \\
\hline Well & 1 & & & & & \\
\hline Moderately & 1.02 & $0.61-1.71$ & 0.931 & & & \\
\hline Poor & 1.45 & $0.89-2.36$ & 0.136 & & & \\
\hline Unknown & 1.85 & $1.16-2.97$ & 0.010 & & & \\
\hline \multicolumn{7}{|l|}{ Sex } \\
\hline Female & 1 & & & & & \\
\hline Male & 0.88 & $0.71-1.08$ & 0.214 & & & \\
\hline \multicolumn{7}{|l|}{ Clinical T stage } \\
\hline $\mathrm{T} 1 / \mathrm{T} 2$ & 1 & & & 1 & & \\
\hline $\mathrm{T} 3 / \mathrm{T} 4$ & 2.01 & $1.57-2.58$ & $<0.001$ & 1.33 & $1.02-1.73$ & 0.036 \\
\hline $\mathrm{Tx}$ & 1.82 & $1.41-2.35$ & $<0.001$ & 1.33 & $1.02-1.74$ & 0.035 \\
\hline Unknown & 3.94 & $2.88-5.39$ & $<0.001$ & 2.22 & $1.57-3.15$ & $<0.001$ \\
\hline \multicolumn{7}{|l|}{ Clinical N stage } \\
\hline N0 & 1 & & & 1 & & \\
\hline N1 & 1.28 & $1.07-1.50$ & 0.006 & 1.21 & $1.02-1.44$ & 0.031 \\
\hline $\mathrm{Nx}$ & 1.50 & $1.25-1.80$ & $<0.001$ & 1.54 & $1.28-1.86$ & $<0.001$ \\
\hline Unknown & 2.70 & $2.11-3.47$ & $<0.001$ & $* *$ & & \\
\hline Supportive therapy (yes) & 1.07 & $0.90-1.27$ & 0.443 & & & \\
\hline Palliative chemotherapy (yes) & 0.46 & $0.39-0.54$ & $<0.001$ & 0.47 & $0.39-0.55$ & $<0.001$ \\
\hline Prior malignancy (yes) & 0.93 & $0.80-1.08$ & 0.358 & & & \\
\hline Increasing age (year) & 1.03 & $1.03-1.04$ & $<0.001$ & 1.02 & $1.01-1.03$ & $<0.001$ \\
\hline
\end{tabular}

Palliative surgery and chemotherapy were associated with a better prognosis in metastatic disease (HR 0.43 and 0.47 respectively, $p<0.001$ ).

\subsection{Quality Control}

In total, 108 patients (16\% of resected patients) underwent a resection in one of the four academic hospitals. One patient $(0.9 \%)$ turned out to have cholecystitis and was incorrectly registered by the NCR as having GBC.

\section{Discussion}

Between 2000 and 2016, no (clinically) significant changes in incidence and survival of GBC were seen. Although radical surgery in early GBC and palliative chemotherapy in unresectable and metastatic GBC significantly improved survival, these treatment modalities were only used in $33 \%$ (radical surgery) and 25\% (palliative chemotherapy) of patients.

The survival rates as demonstrated in this study are comparable to those from a previously published Western cohorts [26,27], but inferior to survival rates from non-Western centers: three-year survival was $73 \%$ for stage I (53\% in stage II) in our study compared to $100 \%$ ( $80 \%$ in stage II) in a recently conducted Korean study including 142 patients [28]. These differences are possibly attributable to selection bias in high-volume expert centers in non-Western countries, different tumor biology or differences in the administration of adjuvant chemotherapy, which has not been standard practice in the Netherlands [29]. 
In a subgroup analysis, improved survival over time was only seen in resected and metastatic GBC. The improved outcome of resected patients is likely the result of multiple factors. Although primary resection rates remained stable, larger tumors (T3/T4) were increasingly resected and 90-day mortality decreased significantly over time, suggesting an improvement in operative techniques or postoperative care. A sharp increase in re-resection rates for early GBC was seen after 2010, coinciding with a change in national guidelines advocating for the use of additional gallbladder bed resection and regional lymphadenectomy in early (pT1b/T2) GBC, which is associated with significantly improved outcomes [14,30-33]. Our results support this notion; patients with early GBC who received radical surgery had a median OS that was over three times larger (76.7 vs. 18.4 months) than the survival of patients who did not undergo radical resection.

Unfortunately, our results suggest substantial undertreatment; even during the last study period only $33 \%$ of patients with early-stage GBC received the recommended radical surgery in addition to cholecystectomy alone. Most likely, the majority of the early GBC patients are diagnosed incidentally after cholecystectomy for suspected benign gallbladder disease by a general gastrointestinal surgeon in a community hospital. We hypothesize that many clinicians still perceive advanced GBC as an untreatable disease and thus may be reluctant to refer patients to a specialized hepatobiliary center for additional surgery or chemotherapy. We believe that multidisciplinary, specialized care, and better adherence to (inter-)national guidelines may improve prognosis of GBC patients.

Previous studies show conflicting results on the value of adjuvant chemotherapy. Most evidence is based on small, retrospective series and only one recently published phase- 3 trial showed a survival benefit in the per-protocol analysis alone [17]. Currently, recruiting large, prospective trials may show more positive results [34]. Unfortunately, the effect of adjuvant therapy after resection could not be assessed as adjuvant therapy is currently not standard of care in the Netherlands and was only administered to a small number of cases (most likely in a clinical trial setting).

In 2010, the ABC-02 trial demonstrated a survival benefit of gemcitabine and cisplatin in metastatic biliary tract cancer [15], resulting in an update of the national guidelines and palliative chemotherapy becoming standard of care. Although a subsequent rise from $15 \%$ to $25 \%$ in the use of palliative chemotherapy was seen after 2010, it was still infrequently administered. Since (subsidized) healthcare insurance is mandatory for all inhabitants of the Netherlands and travel distance to healthcare is generally short, the most likely explanation for this poor delivery rate is nihilism regarding the efficacy of chemotherapy. Evidently, chemotherapy in non-resectable GBC warrants further attention since the increase in use of palliative chemotherapy is a likely cause for the (minor) improvement in median OS in metastatic GBC.

The major limitation of this study pertains to the nature of registration data; because of the retrospective nature of this study, selection bias is present. Caution should be exercised when interpreting results, especially when analyzing treatment strategies and associated differences in survival. Additionally, possible incompleteness of data in the earlier years and changes in registry guidelines resulted in missing data on prognostic factors such as T- and N-stage (16\%) in unresected patients and tumor grade $(29 \%)$ in resected patients.

Second, distinguishing GBC from perihilar cholangiocarcinoma (proximal extrahepatic cholangiocarcinoma, pCC) is challenging in locally advanced disease [35]. Diagnosis in unresected patients was based on imaging only and histopathological confirmation was available in $76 \%$ of patients. However, recent research highlights the importance of this distinction, as GBC and pCC show different molecular landscapes and consequently might benefit from different treatment options [20,36,37]. The results from this study reflect current clinical practice until more reliable diagnostic methods to differentiate between GBC and pCC become available.

A unique strength of this study is the nation-wide, population based design resulting in an accurate representation of treatment and survival patterns of gallbladder cancer in daily clinical practice in a low incidence population. In addition, we were able to perform a quality control and 
demonstrated that the accuracy of the registration data is very high, since only 1 out of 108 patients received an incorrect diagnosis.

\section{Conclusions}

In conclusion, survival of GBC is poor and minimal improvement has been made in the past decade in the Netherlands. Radical surgery in early GBC and palliative chemotherapy in unresectable and metastatic GBC are associated with increased OS. However, the use of these treatment modalities is still limited. A multidisciplinary approach in GBC involving radical surgery and systemic therapy may lead to improvement in the survival of GBC patients.

Author Contributions: Conceptualization, P.d.R., R.v.d.P., E.d.S.L., R.V.; Methodology, P.d.R., R.v.d.P., E.d.S.L., R.V., L.v.d.G.; Software, E.d.S.L., R.V.; Validation, R.V., L.v.d.G.; formal analysis, E.d.S.L.; investigation, E.d.S.L., L.v.d.G.; resources, P.d.R., R.v.d.P., C.v.L., R.V., E.d.S.L., T.d.B., L.v.d.G., J.H., N.H.M., F.D., H.-J.K., T.v.G., J.E., M.d.B., F.H., B.G.K., A.B., J.V., I.N.; data curation, E.d.S.L., T.d.B., L.v.d.G.; writing-original draft preparation, E.d.S.L.; writing—review and editing, P.d.R., C.P., R.V., E.S.L., T.d.B., L.v.d.G., J.H., N.H.M., F.D., H.J.K., T.G., J.E., M.d.B., F.H., B.G.K., E.B., J.V., I.N., P.v.d.B.; visualization, E.d.S.L.; supervision, P.d.R.; project administration, P.d.R., R.v.d.P., R.V., L.v.d.G.; funding acquisition, P.d.R., C.P. Authorship must be limited to those who have contributed substantially to the work reported. All authors have read and agreed to the published version of the manuscript.

Funding: This study was supported by a grant from the ADP foundation (Chamber of Commerce number 55695817). The funding source did not play a role in study design, data collection, data interpretation, data analysis, the writing of the manuscript or the decision to submit the article for publication.

Acknowledgments: Carlijn van de Water provided technical support in the design of the figures.

Conflicts of Interest: The authors declare no conflict of interest.

\section{Appendix A.}

$\begin{array}{lll}\text { ICD-03 code } & & \text { Frequency (\%) } \\ 8000 & \text { Neoplasma } & 310(16.6) \\ 8001 & \text { Tumor cells } & 2(0.1) \\ 8010 & \text { Carcinoma, NOS } & 50(2.7) \\ 8012 & \text { Large cell carcinoma NOS } & 35(1.9) \\ 8013 & \text { Large cell neuroendocrine carcinoma } & 6(0.3) \\ 8020 & \text { Carcinoma, undifferentiated, NOS } & 5(0.3) \\ 8030 & \text { Giant cell and spindle cell carcinoma } & 2(0.1) \\ 8032 & \text { Spindle cell carcinoma, NOS } & 2(0.1) \\ 8033 & \text { Pseudosarcomatous carcinoma } & 3(0.2) \\ 8041 & \text { Small cell carcinoma, NOS } & 10(0.5) \\ 8046 & \text { Non-small cell carcinoma } & 4(0.2) \\ 8070 & \text { Squamous cell carcinoma, NOS } & 19(1.0) \\ 8071 & \text { Squamous cell carcinoma, keratinizing, NOS } & 2(0.1) \\ 8074 & \text { Squamous cell carcinoma, spindle cell } & 1(0.1) \\ 8140 & \text { Adenocarcinoma, NOS } & 1171(62.6) \\ 8144 & \text { Adenocarcinoma, intestinal type } & 21(1.1) \\ 8160 & \text { Cholangiocarcinoma } & 6(0.3) \\ 8163 & \text { Pancreatobiliary-type carcinoma } & 5(0.3) \\ 8210 & \text { Adenocarcinoma in adenomatous polyp } & 7(0.4) \\ 8211 & \text { Tubular adenocarcinoma } & 2(0.1) \\ 8240 & \text { Carcinoid tumor, NOS } & 13(0.7) \\ 8244 & \text { Mixed adenoneuroendocrine carcinoma } & 2(0.1) \\ 8246 & \text { Neuroendocrine carcinoma, NOS } & 6(0.3) \\ 8249 & \text { Atypical carcinoid tumor } & 2(0.1) \\ 8260 & \text { Papillary adenocarcinoma, NOS } & 36(1.9) \\ 8263 & \text { Adenocarcinoma in tubolovillous adenoma } & 3(0.2) \\ 8310 & \text { Clear cell adenocarcinoma, NOS } & 3(0.2) \\ 8312 & \text { Renal cell carcinoma, NOS } & 1(0.1) \\ & & \\ 803 & \end{array}$




$\begin{array}{lll}8350 & \text { Nonencapsulated sclerosing carcinoma } & 1(0.1) \\ 8480 & \text { Mucinous adenocarcinoma } & 31(1.7) \\ 8481 & \text { Mucin-producing adenocarcinoma } & 44(2.4) \\ 8490 & \text { Signet ring cell carcinoma } & 19(1.0) \\ 8500 & \text { Infiltrating duct carcinoma, NOS } & 2(0.1) \\ 8503 & \text { Intraductal papillary adenocarcinoma with invasion } & 4(0.2) \\ 8560 & \text { Adenosquamous carcinoma } & 26(1.4) \\ 8570 & \text { Adenocarcinoma with squamous metaplasia } & 1(0.1) \\ 8574 & \text { Adenocarcinoma with neuroendocrine differentiation } & 10(0.5) \\ 8575 & \text { Metaplastic carcinoma, NOS } & 1(0.1) \\ 8576 & \text { Hepatoid adenocarcinoma } & 1(0.1) \\ 8980 & \text { Carcinosarcoma, NOS } & 3(0.2)\end{array}$

Appendix B. Incidence of Gallbladder Cancer Per 100.000 Inhabitants in the Netherlands, 2005-2016

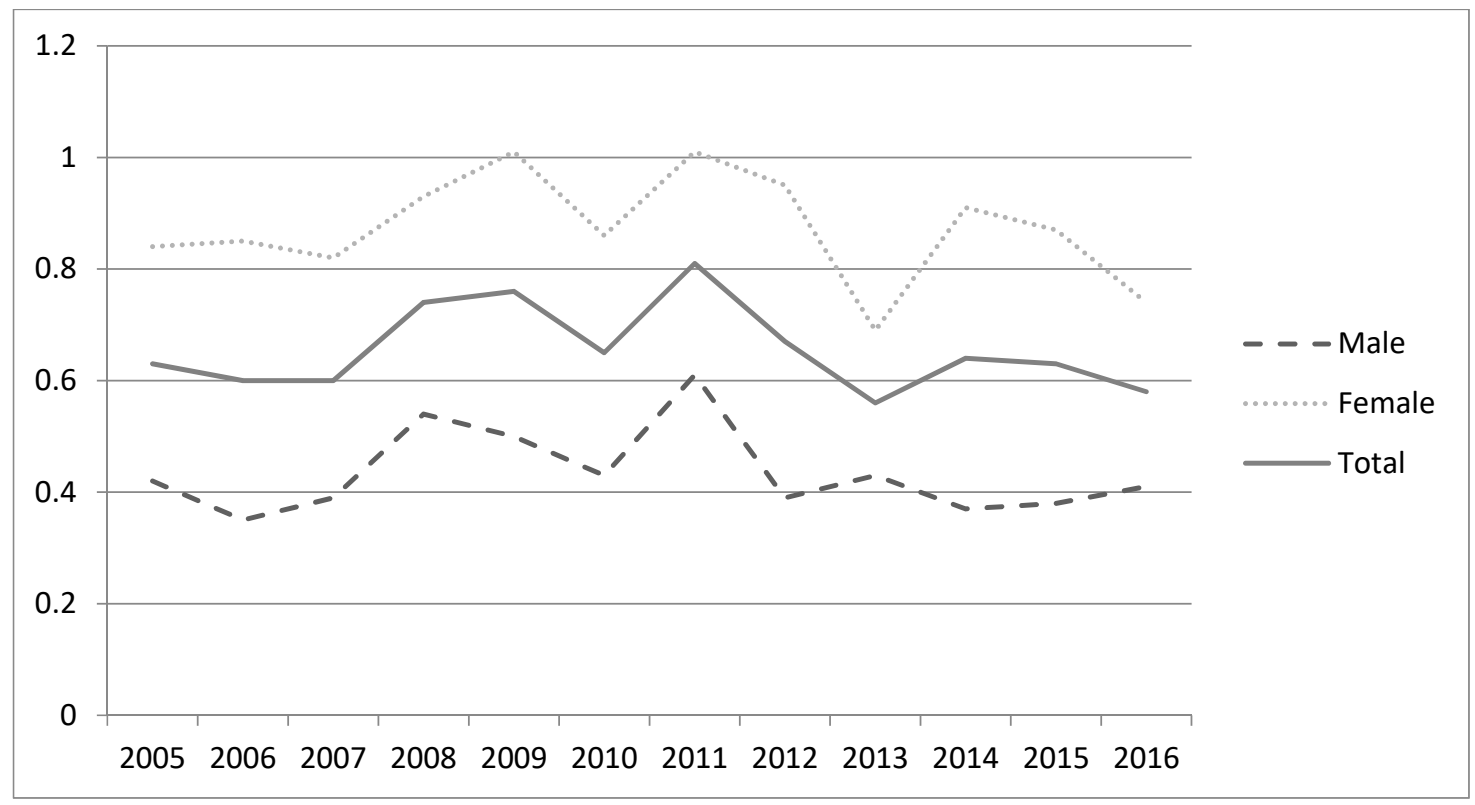

Appendix C. Survival of Gallbladder Cancer Patients by Disease Stage and Period of Diagnosis

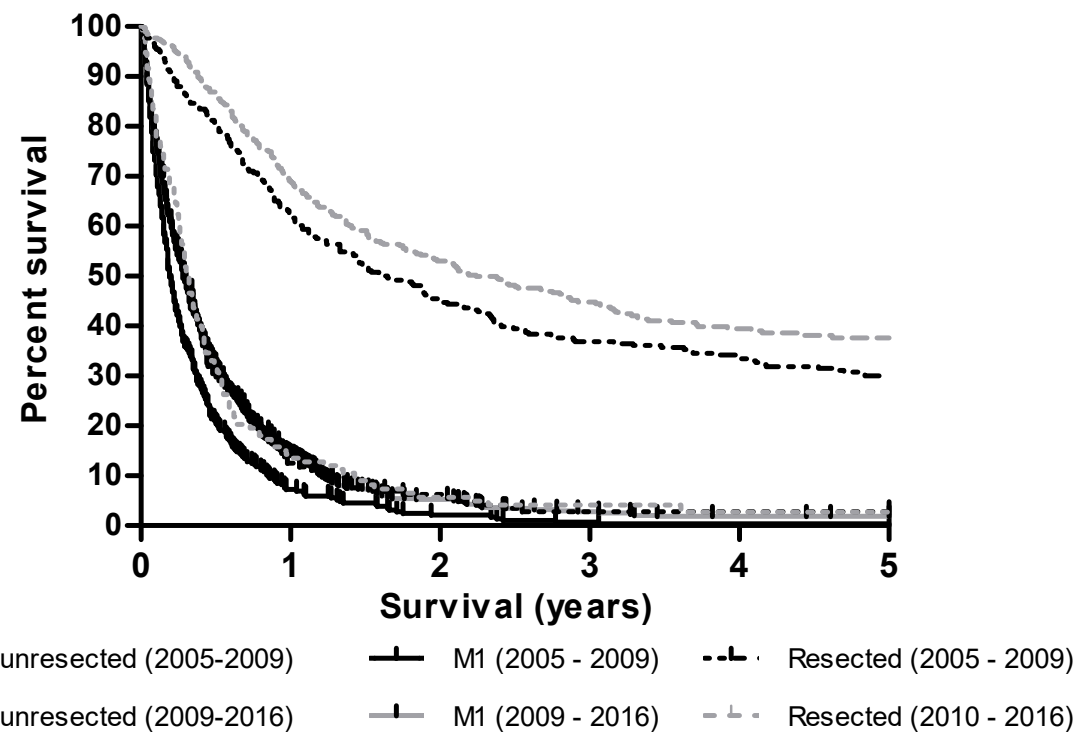




\section{References}

1. Are, C.; Ahmad, H.; Ravipati, A.; Croo, D.; Clarey, D.; Smith, L.; Price, R.R.; Butte, J.M.; Gupta, S.; Chaturvedi, A.; et al. Global epidemiological trends and variations in the burden of gallbladder cancer. J. Surg. Oncol. 2017, 115, 580-590. [CrossRef] [PubMed]

2. Hundal, R.; Shaffer, E.A. Gallbladder cancer: Epidemiology and outcome. Clin. Epidemiol. 2014, 6, 99-109. [PubMed]

3. Piehler, J.M.; Crichlow, R.W. Primary carcinoma of the gallbladder. Surg. Gynecol. Obstet. 1978, 147, 929-942. [CrossRef]

4. Bartlett, D.L.; Fong, Y.; Fortner, J.G.; Brennan, M.F.; Blumgart, L.H. Long-term results after resection for gallbladder cancer. Implications for staging and management. Ann. Surg. 1996, 224, 639-646. [CrossRef] [PubMed]

5. Hueman, M.T.; Vollmer, C.M., Jr.; Pawlik, T.M. Evolving treatment strategies for gallbladder cancer. Ann. Surg. Oncol. 2009, 16, 2101-2115. [CrossRef] [PubMed]

6. Muhammad, J.S.; Khan, M.R.; Ghias, K. DNA methylation as an epigenetic regulator of gallbladder cancer: An overview. Int. J. Surg. (London, England) 2018, 53, 178-183. [CrossRef]

7. Larsson, S.C.; Wolk, A. Obesity and the risk of gallbladder cancer: A meta-analysis. Br. J. Cancer 2007, 96, 1457-1461. [CrossRef]

8. de Martel, C.; Plummer, M.; Parsonnet, J.; van Doorn, L.J.; Franceschi, S. Helicobacter species in cancers of the gallbladder and extrahepatic biliary tract. Br. J. Cancer 2009, 100, 194-199. [CrossRef]

9. Duffy, A.; Capanu, M.; Abou-Alfa, G.K.; Huitzil, D.; Jarnagin, W.; Fong, Y.; D'Angelica, M.; Dematteo, R.P.; Blumgart, L.H.; O'Reilly, E.M. Gallbladder cancer (GBC): 10-year experience at Memorial Sloan-Kettering Cancer Centre (MSKCC). J. Surg. Oncol. 2008, 98, 485-489. [CrossRef]

10. Fong, Y.; Jarnagin, W.; Blumgart, L.H. Gallbladder cancer: Comparison of patients presenting initially for definitive operation with those presenting after prior noncurative intervention. Ann. Surg. 2000, 232, 557-569. [CrossRef]

11. Cubertafond, P.; Gainant, A.; Cucchiaro, G. Surgical treatment of 724 carcinomas of the gallbladder. Results of the French Surgical Association Survey. Ann. Surg. 1994, 219, 275-280. [CrossRef] [PubMed]

12. Buettner, S.; Margonis, G.A.; Kim, Y.; Gani, F.; Ethun, C.G.; Poultsides, G.A.; Tran, T.; Idrees, K.; Isom, C.A.; Fields, R.C.; et al. Changing Odds of Survival Over Time among Patients Undergoing Surgical Resection of Gallbladder Carcinoma. Ann. Surg. Oncol. 2016, 23, 4401-4409. [CrossRef]

13. He, X.D.; Li, J.J.; Liu, W.; Qu, Q.; Hong, T.; Xu, X.Q.; Li, B.L.; Wang, Y.; Zhao, H.T. Surgical procedure determination based on tumor-node-metastasis staging of gallbladder cancer. World J. Gastroenterol. 2015, 21, 4620-4626. [CrossRef] [PubMed]

14. Foster, J.M.; Hoshi, H.; Gibbs, J.F.; Iyer, R.; Javle, M.; Chu, Q.; Kuvshinoff, B. Gallbladder cancer: Defining the indications for primary radical resection and radical re-resection. Ann. Surg. Oncol. 2007, 14, 833-840. [CrossRef]

15. Valle, J.; Wasan, H.; Palmer, D.H.; Cunningham, D.; Anthoney, A.; Maraveyas, A.; Madhusudan, S.; Iveson, T.; Hughes, S.; Pereira, S.P.; et al. Cisplatin plus gemcitabine versus gemcitabine for biliary tract cancer. N. Engl. J. Med. 2010, 362, 1273-1281. [CrossRef]

16. Edeline, J.; Benabdelghani, M.; Bertaut, A.; Watelet, J.; Hammel, P.; Joly, J.P.; Boudjema, K.; Fartoux, L.; Bouhier-Leporrier, K.; Jouve, J.L.; et al. Gemcitabine and Oxaliplatin Chemotherapy or Surveillance in Resected Biliary Tract Cancer (PRODIGE 12-ACCORD 18-UNICANCER GI): A Randomized Phase III Study. J. Clin. Oncol. Off. J. Am. Soc. Clin. Oncol. 2019, 37, 658-667. [CrossRef]

17. Primrose, J.N.; Fox, R.P.; Palmer, D.H.; Malik, H.Z.; Prasad, R.; Mirza, D.; Anthony, A.; Corrie, P.; Falk, S.; Finch-Jones, M.; et al. Capecitabine compared with observation in resected biliary tract cancer (BILCAP): A randomised, controlled, multicentre, phase 3 study. Lancet Oncol. 2019, 20, 663-673. [CrossRef]

18. Ausania, F.; Tsirlis, T.; White, S.A.; French, J.J.; Jaques, B.C.; Charnley, R.M.; Manas, D.M. Incidental pT2-T3 gallbladder cancer after a cholecystectomy: Outcome of staging at 3 months prior to a radical resection. HPB (Oxford) 2013, 15, 633-637. [CrossRef] 
19. Kobayashi, S.; Tomokuni, A.; Gotoh, K.; Takahashi, H.; Akita, H.; Marubashi, S.; Yamada, T.; Teshima, T.; Fukui, K.; Fujiwara, Y.; et al. A retrospective analysis of the clinical effects of neoadjuvant combination therapy with full-dose gemcitabine and radiation therapy in patients with biliary tract cancer. Eur. J. Surg. Oncol. J. Eur. Soc. Surg. Oncol. Br. Assoc. Surg. Oncol. 2017, 43, 763-771. [CrossRef] [PubMed]

20. Valle, J.W.; Lamarca, A.; Goyal, L.; Barriuso, J.; Zhu, A.X. New Horizons for Precision Medicine in Biliary Tract Cancers. Cancer Discov. 2017, 7, 943-962. [CrossRef] [PubMed]

21. Casparie, M.; Tiebosch, A.T.M.G.; Burger, G.; Blauwgeers, H.; Van de Pol, A.; van Krieken, J.H.J.M.; Meijer, G.A. Pathology databanking and biobanking in The Netherlands, a central role for PALGA, the nationwide histopathology and cytopathology data network and archive. Cell. Oncol. Off. J. Int. Soc. Cell. Oncol. 2007, 29, 19-24.

22. Schouten, L.J.; Hoppener, P.; van den Brandt, P.A.; Knottnerus, J.A.; Jager, J.J. Completeness of cancer registration in Limburg, The Netherlands. Int. J. Epidemiol. 1993, 22, 369-376. [CrossRef] [PubMed]

23. von Elm, E.; Altman, D.G.; Egger, M.; Pocock, S.J.; Gotzsche, P.C.; Vandenbroucke, J.P. The Strengthening the Reporting of Observational Studies in Epidemiology (STROBE) statement: Guidelines for reporting observational studies. Lancet (London, England) 2007, 370, 1453-1457. [CrossRef]

24. Greene, F.L.; Page, D.L.; Fleming, I.D.; Fritz, A.G.; Balch, C.M.; Haller, D.G.; Morrow, M. AJCC Cancer Staging Manual, 6th ed.; Springer: New York, NY, USA, 2002.

25. Edge, S.; Byrd, D.R.; Compton, C.C.; Fritz, A.G.; Greene, F.; Trotti, A. ACJJ Cancer Staging Handbook, 7th ed.; Springer: New York, NY, USA, 2010.

26. Witjes, C.D.; Van Den Akker, S.A.; Visser, O.; Karim-Kos, H.E.; De Vries, E.; IJzermans, J.N.; Robert, A.; Coebergh, J.W.W.; Verhoef, C. Gallbladder cancer in the Netherlands: Incidence, treatment and survival patterns since 1989. Dig. Surg. 2012, 29, 92-98. [CrossRef] [PubMed]

27. Hari, D.M.; Howard, J.H.; Leung, A.M.; Chui, C.G.; Sim, M.S.; Bilchik, A.J. A 21-year analysis of stage I gallbladder carcinoma: Is cholecystectomy alone adequate? HPB: Off. J. Int. Hepato Pancreato Biliary Assoc. 2013, 15, 40-48. [CrossRef]

28. Oh, T.G.; Chung, M.J.; Bang, S.; Park, S.W.; Chung, J.B.; Song, S.Y.; Choi, G.H.; Kim, K.S.; Lee, W.J.; Park, J.Y. Comparison of the sixth and seventh editions of the AJCC TNM classification for gallbladder cancer. $J$. Gastrointest. Surg. Off. J. Soc. Surg. Aliment. Tract 2013, 17, 925-930. [CrossRef] [PubMed]

29. IKNL. Galweg-en Galblaascarcinoom 2.0; IKNL: Utrecht, The Netherlands, 2010.

30. Koerkamp, B.G.; Jarnagin, W.R. Surgical Oncology: A Practical and Comprehensive Approach; Springer: New York, NY, USA, 2015; pp. 235-255.

31. Lee, S.E.; Jang, J.Y.; Lim, C.S.; Kang, M.J.; Kim, S.W. Systematic review on the surgical treatment for T1 gallbladder cancer. World J. Gastroenterol. 2011, 17, 174-180. [CrossRef] [PubMed]

32. Goetze, T.O.; Paolucci, V. Immediate re-resection of T1 incidental gallbladder carcinomas: A survival analysis of the German Registry. Surg. Endosc. 2008, 22, 2462-2465. [CrossRef]

33. Coburn, N.G.; Cleary, S.P.; Tan, J.C.; Law, C.H. Surgery for gallbladder cancer: A population-based analysis. J. Am. Coll. Surg. 2008, 207, 371-382. [CrossRef]

34. Skipworth, J.R.; Olde Damink, S.W.; Imber, C.; Bridgewater, J.; Pereira, S.P.; Malago, M. Review article: Surgical, neo-adjuvant and adjuvant management strategies in biliary tract cancer. Aliment. Pharmacol. Ther. 2011, 34, 1063-1078. [CrossRef]

35. Hennedige, T.P.; Neo, W.T.; Venkatesh, S.K. Imaging of malignancies of the biliary tract- an update. Cancer Imaging 2014, 14, 14. [PubMed]

36. Javle, M.; Bekaii-Saab, T.; Jain, A.; Wang, Y.; Kelley, R.K.; Wang, K.; Kang, H.C.; Catenacci, D.; Ali, S.; Krishnan, S.; et al. Biliary cancer: Utility of next-generation sequencing for clinical management. Cancer 2016, 122, 3838-3847. [CrossRef] [PubMed]

37. Ahn, D.H.; Bekaii-Saab, T. Biliary cancer: Intrahepatic cholangiocarcinoma vs. extrahepatic cholangiocarcinoma vs. gallbladder cancers: Classification and therapeutic implications. J. Gastrointest. Oncol. 2017, 8, 293-301. [CrossRef] [PubMed]

(C) 2020 by the authors. Licensee MDPI, Basel, Switzerland. This article is an open access article distributed under the terms and conditions of the Creative Commons Attribution (CC BY) license (http://creativecommons.org/licenses/by/4.0/). 